\title{
"YOU TIDES WITH CEASELESS SWELL": A Reading of the Manuscript
}

\author{
Geoffrey M. Sill
}

WALT WhITMAN WAS SIXTY-FIVE years old when he wrote the sequence of eight poems known as "Fancies at Navesink" which forms the heart of the "Annex" in some of the copies of the 1884 reprinting of the 1881 edition of Leaves of Grass. Many of his critics, then and now, believe he was written out by 1884 , a sick old man repeating himself without the ability to distinguish between poetry and the unmitigated expressions of his ego. But Harold Blodgett and Sculley Bradley said of the "Fancies at Navesink" sequence that it "takes its place with the 'Sea-Drift' cluster, which it indeed surpasses with respect to the sustained unity of theme and mood" among Whitman's best work on one of his favorite subjects, the sea. ${ }^{1}$ And a close examination of the poems, especially in comparison with the surviving manuscripts, shows that the Whitman of the early 1880 s was a meticulous craftsman who knew and worked within traditional poetic forms, while still capable of launching his soul, however briefly, into those cosmic regions he had mapped out in such "Sea-Drift" poems as "Crossing Brooklyn Ferry" and "Out of the Cradle Endlessly Rocking."

Though the eight "Fancies at Navesink" poems comprise only two and one-half pages of printed text in the 1884, 1888, and 1892 editions of Leaves of Grass, and total only 61 full lines of poetry, there are 18 pages of manuscript for these poems at Yale University, and 54 more fragments in the Feinberg collection at the Library of Congress, with other fragments reported in other locations. ${ }^{2}$ The abundance of manuscripts for such a small body of published work is an indication of the labor that Whitman expended on these poems. But one of the manuscripts, the first draft of the poem "You Tides with Ceaseless Swell," is particularly rich in evidence about Whitman's process of composition and his values as a poet. This manuscript, in private hands until 1981, is currently in the collection of the Walt Whitman Association at the poet's Mickle Street home in Camden, New Jersey.

The Whitman Association manuscript is a single page, 121/4 inches long, made up of eleven manuscript fragments cut into single strips and pasted on top of one another as the poet shifted stanzas around and interlineated new work (see facsimile on the back cover). Like the fragments at Yale and the Library of Congress, the title and stanzas are written in Whitman's hand in the heavy India ink he favored, while the cancellations and interlineations are 
made, also in his hand, not only in the same black ink, but also in both black lead and purple pencil, which suggests that the poet invested at least four different work sessions on the poem. The fragments are written on the backs of letters sent to Whitman (or, in the case of one fragment, perhaps to his brother George) by various correspondents. The title and first stanza (later canceled), which may indicate the point after which composition of the poem began, are written on the back of a letter on New York Tribune stationery from Whitelaw Reid, addressed to Whitman at 431 Stevens Street and dated July 17, 18-. The last two digits of the date have been cut off, but the letter is almost certainly Reid's response to Whitman's letter of July $12,1878 .^{3} \mathrm{An}$ other fragment bears the date January 8,1884 . Thus, the poem was begun no earlier than July, 1878, and was finished no earlier than the first months of 1884. I offer here a transcription of the Whitman Association manuscript followed by the text of the published version of "You Tides with Ceaseless Swell" (1884; 1888; 1891-92):

You tides with Ceaseless Swell and ebb.

You tides with ceaseless swell and ebb! you taw that does this work!

unseen entire!

You unseen force, centripetal, centrifugal, through Space's Spread ${ }_{\wedge}$ you systole, diastolel

You unseen

What ${ }_{\Lambda}$ intermutual ${ }_{\Lambda}$ chain $\$$ of sun, moon, and brother worlds of spacel

all the myriad stars?

constellations!

are the are the by you stars through you?

What ${ }_{\Lambda}$ messages by you it ${ }_{\Lambda}$ from distant ${ }_{\Lambda}$ worlds to us ${ }_{\Lambda}$ ? What Sirius'? What Capella's?

strong central within sent forth

What ${ }_{\wedge}$ heart-and you the $\wedge$ pulse-vivifies all? What boundless ${ }_{\wedge}$ aggregate of all?

every limitless-Spreat of
What clue to all the forces that act through ${ }_{\Lambda}$ Space('s)entire-centripetal,
centrifugal?

subtle in you? liquid watle-

What liquidindirection and significance? What fluid ${ }_{\wedge}$ vast identity,

as

Holding the universe ${ }_{\wedge}$ one, -as sailing in a Ship?

You Tides with Ceaseless Swell.

You tides with ceaseless swell! you power that does this work!

You unseen force, centripetal, centrifugal, through space's spread,

Rapport of sun, moon, earth, and all the constellations,

What are the messages by you from distant stars to us? what Sirius'?

what Capella's? 
What central heart -and you the pulse-vivifies all? what boundless aggregate of all?

What subtle indirection and significance in you? what clue to all in you? what fluid, vast identity,

Holding the universe with all its parts as one-as sailing in a ship?

Of the many significant differences between the Whitman Association manuscript and the published versions of the poem, perhaps the most striking is the title. The manuscript has "You tides with Ceaseless Swell and ebb" as the title, while the published version has only "You Tides with Ceaseless Swell." The title is derived from the first line, which similarly had "You tides with ceaseless swell and ebb! You power that does this work!" in manuscript, but only "You tides with ceaseless swell! You power that does this work!" in the printed version. What caused Whitman to drop the words "and ebb" from the final version? The poem, after all, makes better sense with those words in place, because a tide that ceaselessly swelled and never ebbed would have inundated the world's land mass long ago. A reader who insists on reading the "Fancies at Navesink" cluster as a whole, as a single essay on the sea, might argue that the ebb tide is taken care of in the next poem, "Last of Ebb, and Daylight Waning," but it strains credulity to think that Whitman would have hoped to repair a flaw in the meaning of one poem by making it up in the next. A more obvious and convincing reason for the omission of "and ebb" is that, in its final form, the line "You tides with ceaseless swell! You power that does this work!" is a perfect Alexandrine, a 6-foot iambic line with three stressed syllables on each side of a caesura, represented by the interior punctuation. The words "and ebb," however necessary to the meaning, would have thrown the line out of balance by adding two syllables and one stress to the first half of the line. The point is underscored by Roger Asselineau's observation that it was in this period that Whitman began to pay particular attention to the way that the title and first line set up the tone and structure of a poem. ${ }^{4}$

However, lest it seem that Whitman was a prisoner of metrical regularity, it should be noted that the manuscript originally referred to the "law" that drives the tides, not the "power." "Law" was a good choice to fit the meter, but Whitman rejected it in the process of revision in favor of "power," perhaps to give the poem a more mystical, religious quality than "law" could convey. "Power" contains an extra unstressed syllable, but the improvement in implication is well worth the slight variation in meter, particularly when the variation is unstressed.

This same attention to meter appears to have determined the composition of the second line of the poem. In its final, published form, the line is sixteen syllables long, divided evenly into four groups of four syllables each, which scan as follows:

You únseen force, $\mid$ centripetal, $\mid$ centrifúgăl, $\mid$ through spacés spread 
The two pairs of iambs at the beginning and end of the line balance and enclose the alliterative, sprung-dactyllic pair of words, "centripetal, centrifugal," which catch at once the whirling, outward-flinging motion of the stars and the rolling, repetitive coming-around-again movement of the tides. These words, so similar as phonemes but so radically opposed in meaning, create tension in the line as they express the opposing forces of nature that drive the tides, thereby creating in the line a perfect marriage of language and meaning.

The manuscript, however, tells us that the words were not at first so well or so prominently placed. They had come to Whitman at the end of the fifth fragment, a very rough, prosy line that read

\author{
every limitless \\ What clue to $\Lambda$ ll the-force(s) that act(s) through ${ }_{\Lambda}$ Space('s) \\ Spread of \\ ${ }_{\wedge}$ entire-centripetal, centrifugal?
}

One sees here the idea finally captured in what became the second line of the poem, and some of the basic elements: as its subject, a force which could only be known by clues (later, "unseen force"); the vastness of space described simply (and effectively) as its "spread." In a more traditional poet's hands, the line might easily have become iambic pentameter, reminiscent of Pope or Dryden:

\title{
You únseěn force, through space's spread ěntire
}

But Whitman resisted this easy solution in favor of the bold stroke by which he encapsulated "centripetal, centrifugal" as the dynamic center of an otherwise stodgy line, while maintaining the graceful formality with which the first line had begun the poem.

It is interesting that, even after Whitman had re-written the first and second lines together in black lead pencil and pasted them in on top of his original first stanza, he kept tinkering with the second line, trying to improve upon it. He crossed out "unseen," and then restored it; he tried to sneak "entire" back into the line after "space's spread," and left it there until the proof stage; he added a superfluous "You systole, diastole!" in an effort to emphasize the quasi-mechanical operation of the universe. None of these emendations is objectionable from the standpoint of sense; what is wrong with all of them is that they disrupted the formal beauty and integrity of the line.

The rhythms of the remaining lines in the poem are also interesting, but rather than examine them in depth, we should look at the formal structure of the poem itself for more insights into Whitman's rhetorical methods. Perhaps the first thing we notice is that the main body of the poem - in the Whitman Association manuscript, the second through sixth fragments - are all in- 
terrogatories, beginning with "What" followed by a noun, or noun modified by an adjective: "What intermutual chains," "What messages," "What heart," "What clue," "What liquid indirection. ..." The interrogatories constitute a rhetorical structure that holds the poem together while casting the speaker as an asker of questions that have no immediate answers, and postpone the climax of the poem while they extend the range and detail of the speaker's wonder at the operation of the tides. The first stanza of the manuscript, however - the two lines analyzed above in terms of their rhythms - are radically different in their rhetorical stance, being direct addresses by the speaker to the tides and the forces that drive them. A peek beneath the pasted-on fragment on which Whitman re-wrote those first two lines reveals that his first draft of them, too, had employed the direct address between the speaker and the tides. In other words, from the very beginning, it was Whitman's rhetorical strategy to open the poem by positing a speaker (the implied "I" who addresses the tides as "You"), and then to broaden the scope of the poem by turning from the tides to the larger questions they raise, by means of the interrogatories. The reader, identifying with this implied "I," or at least looking over its shoulder, is thus invited to participate with Whitman in a dialogue that is both celebratory and confrontational.

The Whitman Association manuscript version of the poem thus shows a very abrupt transition - or perhaps, no transition at all-from the direct address of the first two lines to the interrogatories of the poem's body. The published version, however, does contain a transitional line:

Rapport of sun, moon, earth, and all the constellations

and omits the entire second stanza of the manuscript. Where did this lineutterly at odds with the parallel syntactical structures of the rest of the poem-come from, and in what sense is it transitional? For the answer, we must look at the heavily revised, and finally discarded second stanza:

You
What $\wedge$ intermutual $\wedge$ chains of sun, moon, and earth, and
brother-worlds of space!
all the myriad-stars?
constellations!

It is evident that Whitman saw the need for a transitional line from the "You" to the "What" structure, and tried to make it by substituting "You" for "What" in this line. That solution had the disadvantage of merely postponing the transition for another line, and additionally put the speaker in the uncomfortable position of addressing unseen, intermutual chains linking our solar system to the stars - a tall order even for a visionary like Whitman. In the end, perhaps as late as the proof stage, he scrapped both "You" and "What" 
and settled on a neutral third term, "Rapport," with which to open the line. The noun "rapport" functions as a summative modifier describing the relationship of the tides and the stars, belonging neither to the "you" or the "what" but serving as a pivot that allows the speaker to turn from addressing the tides to questioning the messages of the stars. The change also allows Whitman to replace the arrhythmic "intermutual" with the much more graceful "rapport," an iambus that establishes a rhythm for the entire line. In its final form, the line may be scanned as follows:

$$
\text { Rappórt | ơf sún, | moon, | earth, | and all | the constellations }
$$

which gives Whitman the same six-stress line as the first two lines of the poem, and yet, being "sprung" in its rhythm by the use of two single-syllable feet and a long final foot containing four unstressed syllables, opens the door to the arrhythmic interrogatories that follow.

Though arrhythmic, the interrogatories are not without structure. Besides being linked by the initial "What," each contains a caesura, punctuated with a question mark, after which the line is resumed with another "What." One objection Whitman may have had to the canceled fifth stanza - which led him to revise it for use as the critically important second line of the poem-is that it does not fit the pattern of the other interrogatories, having no caesura and no internal "What." Each of the interrogatories employs the zeugma that is common in eighteenth-century neo-classical poetry-the linking word implied in both halves of the line, but present in only one of them. Thus, the word "messages" is the subject of the first interrogatory, and is implied in the possessive punctuation of the two stars named in the second half of the line-that is, Sirius' message, and Capella's:

What are the messages by you from distant stars to us? what Sirius'? what Capella's?

In the second interrogatory, the phrase "what boundless aggregate of all" is nonsensical unless read as "what vivifies the boundless aggregate of all," importing the verb from the first half of the line. In the final interrogatory, the zeugma becomes particularly complex and important. The Whitman Association manuscript clearly reveals that Whitman deliberately created the zeugma by inserting the phrase "in you" in the first half of the line, and omitting it in the second:

subtle in you? liquid-oubtleWhat iquid ${ }_{\Lambda}$ indirection and significance? ${ }_{\Lambda}$ What fluid ${ }_{\Lambda}$ vast identity

This is close to the final version, but perhaps Whitman felt that the line was not strong enough to be the second-to-last in the poem, or perhaps he re- 
gretted not having been able to use the word "clue" to express the message of the tides, which he had endeavored to introduce into the manuscript twice before without finding a suitable place. For whatever reason, he lengthened the line to read:

\section{What subtle indirection and significance in you? What} clue to all in you? What fluid, vast identity

carefully preserving a structure consistent with that of the other interrogatories, while moving the zeugma to the very end of the line, thereby allowing the momentum of the poem to flow smoothly into the last line.

The last line of the published version seems (to this reader) to be the weakest line of the poem. It is introduced by a participle, "Holding," which attaches uncomfortably to the word "identity" that precedes it; only by adding the explanatory phrase "with all its parts as one" does the speaker manage to let us know that we are to see in the word "identity" the sense of "entity," or a self that unifies many diverse parts. The first participle is followed by another - "as sailing in a ship"-even more strange: where did the metaphor of a ship come from, in this poem about tides and stars? The mystery is partly alleviated, and the line given more meaning, when it is noticed that there are two descending pen strokes above the words "Holding" and "the" in the manuscript. The descenders are from the word "aggregate" three stanzas above, to which this last fragment used to be attached:

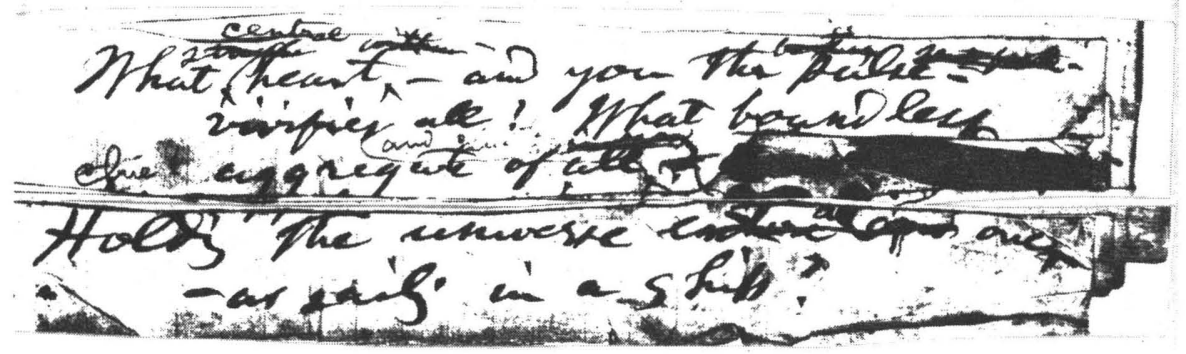

Thus the end of the poem had initially read,

\footnotetext{
What heart-and you the pulse-vivifies all? What boundless aggregate of all,

Holding the universe entire - as sailing in a ship?
}

The participle "holding" had originally been attached to the phrase "aggregate of all," which more easily conveys the idea of a whole containing many parts, and is more easily visualized as a ship containing sailors of many nations, all pursuing a common course through a boundless ocean. The original referent of the participle had made unnecessary the prosaic phrase "with all 
its parts as one," which weakens the last line in its efforts to explain the way in which a ship is like a universe of stars.

Yet, even if it is granted that the poem ends weakly, it still bears out Roger Asselineau's observation that Whitman became "increasingly mindful of form" in the late 1870s and early 1880s, and in so doing he reached a level of formal art that had eluded him before. ${ }^{5}$ Furthermore, "You Tides" confirms Asselineau's remark that Whitman's best work often grew out of prose entries in his notebook. ${ }^{6}$ Two entries in Specimen Days, "A Winter Day on the Sea-Beach" and "Sea-Shore Fancies," bear close resemblance to the poem, and appear to have given rise to the entire "Fancies at Navesink" cluster. The two prose pieces describe the poet's thoughts during a day trip in December 1876 to the New Jersey shore. Whitman walked "along the beach, or in sight of the ocean, listening to its hoarse murmur" for a total of more than four and one-half hours, with a dinner break of two hours in the middle- long enough to have seen both the ebbing and swelling tides. ${ }^{7}$ After describing the scene, he breaks into an apostrophe on the effects of the ocean upon him that is not unlike the language of "You Tides with Ceaseless Swell," complete with interrogatories:

The attractions, fascinations there are in sea and shore! How one dwells on their simplicity, even vacuity! What is it in us, arous'd by those indirections and directions?

Whatever it is that the sea arouses in Whitman-he describes its effect as "so indescribably comforting, even this winter day-grim, yet so delicate-looking, so spiritual" - the response is not a momentary, transitory one. Whitman confesses that he has had these feelings since his childhood on Long Island, and that he has always intended to try to express them in poetry:

Even as a boy, I had the fancy, the wish, to write a piece, perhaps a poem, about the seashore - that suggesting, dividing line, contact, junction, the solid marrying the liquid-that curious, lurking something, (as doubtless every objective form finally becomes to the subjective spirit,) which means far more than its mere first sight, grand as that is-blending the real and the ideal, and each made portion of the other.

Once at Montauk, he recalls, "I felt that I must one day write a book expressing that mystic, liquid theme." Whitman remarks that he continues to be haunted by the sea's "mystic theme," even though the poems in the "SeaDrift" cluster were already behind him in 1876; it is apparent that he feels that he has not finished with the shore. He never did write an entire book on that theme, but in the "Fancies at Navesink" sequence he returned to it once more, and in the poem "You Tides with Ceaseless Swell," he gave his answer to the question, "What is it in us, arous'd by those indirections and directions?" 


\section{NOTES}

1 Harold Blodgett and Sculley Bradley, eds., Leaves of Grass, Comprehensive Reader's Edition (New York: New York University Press, 1965), 514.

2 Blodgett and Bradley describe the manuscripts at Yale, and mention other fragments in the Barrett, Berg, Hanley, and Huntington collections. The fragments in the Library of Congress are described in Walt Whitman: A Catalog based upon the Collections of the Library of Congress, with notes by Charles Feinberg (Washington: U.S.G.P.O., 1955), item 30. Feinberg's note (accepted by Blodgett and Bradley ) that the "Fancies at Navesink" sequence was "first published in The Nineteenth Century, August 1885" appears to be in error, because the sequence is found in the "Annex" to the so-called "freak" copies of the 1884 David McKay Co. reprinting of the 7th (1881) edition of Leaves of Grass. One of these copies is in the collection of the Walt Whitman Association.

3 Edwin Haviland Miller, ed., Walt Whitman, The Correspondence (New York: New York University Press, 1964), 3:129. Miller has Whitman's letter to Reid, but not the reply; he notes, however, that the reply is owned by Mrs. Doris Neale, who donated the manuscript of "You tides with Ceaseless Swell" to the Association in 1981. Miller's reference appears to be to the verso of the manuscript.

4 Roger Asselineau, The Evolution of Walt Whitman (1962), excerpted in Walt Whitman, A Critical Anthology, ed. Francis Murphy (Harmondsworth: Penguin, 1969), 401.

5 Asselineau, 402.

6 Asselineau, 405-406.

7 All of the quotations from "A Winter Day on the Sea-Beach" and "Sea-Shore Fancies" are from Walt Whitman, Complete Prose Works (Boston: Small, Maynard \& Co., 1898), 87-89. 